\title{
Dopamine wide range detection sensor based on modified Co3O4 nanowires electrode
}

\author{
Sami Elhag, Zafar Hussain Ibupoto, Xianjie Liu, Omer Nur and Magnus Willander
}

\section{Linköping University Post Print}

\section{Tweet}

N.B.: When citing this work, cite the original article.

Original Publication:

Sami Elhag, Zafar Hussain Ibupoto, Xianjie Liu, Omer Nur and Magnus Willander, Dopamine wide range detection sensor based on modified Co3O4 nanowires electrode, 2014, Sensors and actuators. B, Chemical, (203), 543-549.

http://dx.doi.org/10.1016/j.snb.2014.07.028

Copyright: Elsevier

http://www.elsevier.com/

Postprint available at: Linköping University Electronic Press

http://urn.kb.se/resolve?urn=urn:nbn:se:liu:diva-111254 


\title{
Dopamine wide range detection sensor based on modified $\mathrm{Co}_{3} \mathrm{O}_{4}$ nanowires electrode
}

Sami Elhag, ${ }^{* a}$ Zafar Hussain Ibupoto ${ }^{\mathrm{a}}$, Xianjie Liu ${ }^{\mathrm{b}}$, Omer Nur, ${ }^{\mathrm{a}}$ and Magnus Willander ${ }^{\mathrm{a}}$.

${ }^{a}$ Department of Science and Technology, Linköping University, Campus Norrköping, SE-60174 Norrköping, Sweden

${ }^{\mathrm{b}}$ Department of Physics, Chemistry, and Biology (IFM), Linköping University, 58183 Linköping Sweden

\begin{abstract}
Ultra-thin cobalt oxide $\left(\mathrm{Co}_{3} \mathrm{O}_{4}\right)$ nanowires grown on gold coated glass substrates by the hydrothermal chemical deposition and have been used as a wide range dopamine potentiometric sensor. An anionic surfactant (sodium dodecylbenzenesulfonate) was used to achieve assisted growth procedure. Moreover, a polymeric membrane containing polyvinyl chloride as plasticized polymer, $\beta$-cyclodextrin as ionophore, and potassium tetrakis (4chlorophenyl) borate as ionic additive were immobilized on the $\mathrm{Co}_{3} \mathrm{O}_{4}$ nanostructures through electrostatic adsorption method. X-ray diffraction, x-ray photoelectron spectroscopy, and scanning electron microscopy were used to characterize the electrodes while ultravioletvisible absorption was used to investigate the band gap of the $\mathrm{Co}_{3} \mathrm{O}_{4}$ nanostructures. The structural characterization showed a cubic crystalline, pure phase, and nanowires morphology of the $\mathrm{Co}_{3} \mathrm{O}_{4}$. However, the morphology is altered when the surfactant concentration has been changed. The $\mathrm{Co}_{3} \mathrm{O}_{4}$ chemical modified electrodes were used in potentiometric measurements for dopamine in a $10^{-2} \mathrm{M}$ acetic acid/sodium acetate solution having a $\mathrm{pH}$ of 5.45 . For dopamine range from $10^{-9} \mathrm{M}$ to $10^{-2} \mathrm{M}$, the potential response of the sensor electrode was linear with a slope of $52 \mathrm{mV} /$ decade. The wide range and high sensitivity of the modified $\mathrm{Co}_{3} \mathrm{O}_{4}$ nanowires based sensor for dopamine is attributed to the defects on the metal oxide that is dictated by the used surfactant along with the high surface area-to-volume ratio.
\end{abstract}

Key words: Potentiometric sensor, chemically modified electrode, surfactant, and dopamine chemical sensor.

\footnotetext{
* Author to whom correspondence should be addressed; E-Mail: sami.elhag @liu.se; Tel.: +46-11-36-3035; Fax: $+46-11-36-3270$
} 


\section{Introduction}

To date, miniaturized chemical sensors sensitivity and limit of detection (LOD) are being intensely pursued in medical, environment, and chemical sciences [1-5]. Traditional potentiometric sensors usually employ an indicator electrode which can be an ion-selective electrode (ISE), redox electrode etc... and is used in sensing against a reference electrode $[6,7]$. On the other hand, the sensor electrode size requirement makes use of chemically modified electrodes (CMEs) desirable option [8,9]. The fabrication of a thermodynamically stable electrochemical interface for a CME is a challenging task and it was suggested to use either an ISE membranes that contains an appropriate redox-active component, such as a lipophilic silver complex, or to contact the inner electrode via an intermediate polymer layer that is redox-active or has both electronic and ionic conductivity [10].

The biocompatibility, excellent electro-catalytic activities, and fast electron transfer kinetics accompanied with a high surface area to volume ratio; are properties of metal oxide nanostructures that gave a potential for their use in sensing [11-13]. Further, metal oxide nanostructures based sensor detection can effectively be improved by the physical or a chemical modification of electrode surface. Among these metal oxide nanostructures is cobalt oxide $\left(\mathrm{Co}_{3} \mathrm{O}_{4}\right)$ also called tricobalt tetroxide and cobaltosic oxide [14]. $\mathrm{Co}_{3} \mathrm{O}_{4}$ has been commonly used in energy storage [15] heterogeneous catalysts [16], sensor [17], and electrochromic devices [18]. $\mathrm{Co}_{3} \mathrm{O}_{4}$ is a p-type and is magnetic semiconductor material has both direct and indirect band gaps of $2.10 \mathrm{eV}$ and $1.60 \mathrm{eV}$, respectively [19]. It has a cubic spinel structure with magnetic $\mathrm{Co}^{2+}$ ions distributed on tetrahedral sites and non-magnetic $\mathrm{Co}^{3+}$ ions on octahedral sites. Furthermore, $\mathrm{Co}_{3} \mathrm{O}_{4}$ is an ionic semiconductor with positively polar termination having two $\mathrm{Co}^{2+}$, two $\mathrm{Co}^{3+}$, and four $\mathrm{O}^{2-}$ ions and negatively polar termination with two $\mathrm{Co}^{3+}$ and four $\mathrm{O}^{2-}$ ions [20]. Thus, the diversity of these polar sites combined with the relatively large surface area to volume ratio of the $\mathrm{Co}_{3} \mathrm{O}_{4}$ nanostructures will not only help to easily detect the charges but also provide much electron transfer process on the electrode surface.

Recently, we have reported a simple potentiometric method for detecting dopamine (DA) molecules based on $\mathrm{ZnO}$ nanorods see [21]. DA is a potential neurotransmitter in the brain, and the abnormal dopamine receptor signaling and the dopaminergic nerve function are involved in several neurological disorders. In our previous sensor based on $\mathrm{ZnO}$ nanorods the DA concentrations range achieved were between $1 \times 10^{-6} \mathrm{M}$ and $1 \times 10^{-1} \mathrm{M}$, with sensitivity 
of $49 \mathrm{mV} /$ decade. The focus of the present paper is the use of $\mathrm{Co}_{3} \mathrm{O}_{4}$ nanostructures based modified electrodes to further increase the sensitivity and obtain a lower LOD. We have used an anionic surfactant so called sodium dodecyl benzene sulfonate (SDBS). Surfactants are used to tune the morphology of the grown nanostructures [22, 23] and improve the performance of an electrode [24]. We have used different complementary techniques to characterize the grown material and fabricated a sensitive wide detection range dopamine sensor.

\section{Materials and Methods}

\subsection{Synthesis of $\mathrm{Co}_{3} \mathrm{O}_{4}$ nanostructures}

Glass substrates were sonicated in ultrasonic bath for about $10 \mathrm{~min}$. in acetone, deionized water, and isopropanol respectively and were finally dried by flowing air gun. The substrates were then fixed into vacuum chamber of an evaporator instrument (Satis CR 725). After this an adhesive layer of $20 \mathrm{~nm}$ of titanium was evaporated on the substrates and followed by a $100 \mathrm{~nm}$ thickness layer of gold thin film. Then the metal coated substrates were seeded with cobalt acetate anhydrous layer via spin coating technique at $1000 \mathrm{rpm}$. This process was repeated three times and then the samples were annealed at a temperature of 120 ${ }^{0} \mathrm{C}$ for $5 \mathrm{~min}$. The substrates were fixed upside down in a solution containing $100 \mathrm{~mL}$ deionized water solution, urea and cobalt chloride of equimolar $(0.1 \mathrm{M})$ and in addition to SDBS of different concentrations. The SDBS concentrations used were 1.4, and $2.9 \mathrm{mM}$, respectively. These different SDBS concentrations were chosen to tune the morphology of the grown $\mathrm{Co}_{3} \mathrm{O}_{4}$. After completion of the growth duration, the samples were washed with deionized water and dried at room temperature. The resulting cobalt hydroxide nanostructures were annealed at $450{ }^{\circ} \mathrm{C}$ for 3 hours for the conversion of the hydroxide phase of cobalt into crystalline oxide phase.

\subsection{Membrane and indicator electrodes preparation}

The membrane and the buffer solution were prepared using powdered polyvinyl chloride (PVC) (0.18 g) as plasticized polymer which was dissolved in tetrahydrofuran (6 $\mathrm{mL}$ ), and mixed with $\beta$-cyclodextrin ( $\beta$-CD) used as ionophore $(0.04 \mathrm{~g})$, potassium tetrakis (4chlorophenyl) borate as ionic additive $(0.01 \mathrm{~g})$, and 2-fluoro-2'-nitrodiphenyl ether $(0.4 \mathrm{~g})$. All reagents were of analytical grade and were used without being submitted to any additional purification. All the chemicals were purchased from Sigma-Aldrich. The as grown $\mathrm{Co}_{3} \mathrm{O}_{4}$ 
nanostructures were dipped three times into the membrane solution. After that all the electrodes were left to dry in a fume hood at room temperature for one night. All the functionalized sensor electrodes were kept in a free water vapor moisture environment at room temperature when not in use.

\subsection{Characterizations}

The crystal quality of the cobalt oxide nanostructures was studied by $\mathrm{x}$-ray powder diffraction (XRD) using a Phillips PW 1729 powder diffractometer equipped with CuKa radiation $(\lambda=1.5418 \AA)$ using a generator voltage of $40 \mathrm{kV}$ and a current of $40 \mathrm{~mA}$. The surface and chemical composition analyses were investigated by $\mathrm{x}$-ray photoelectron spectroscopy (XPS) technique and were measured by vacuum generators ESCA200 using a monochromatic $\mathrm{Al}(\mathrm{K} \alpha)$ radiation. The morphology and structural properties of the $\mathrm{Co}_{3} \mathrm{O}_{4}$ nanostructures were examined by LEO 1550 Gemini field emission scanning electron microscope (SEM) operated at different voltages. The electrochemical potential have been measured by a functionalized $\mathrm{Co}_{3} \mathrm{O}_{4}$ nanostructures based indicator electrodes and were measured against a silver-silver chloride as reference electrode at room temperature using an electrical instrument (Keithley 2400). Optical absorption spectra were obtained by a PerkinElmer Lambda $900 \mathrm{UV}-$ visible spectrophotometer. $\mathrm{Co}_{3} \mathrm{O}_{4}$ nanostructures grown on glass substrate were used for the measurements. A blank glass slide was used as reference.

\section{Result and discussions}

\subsection{Morphology and structural characteristics}

The XRD pattern of the annealed sample of $\mathrm{Co}_{3} \mathrm{O}_{4}$ nanostructures are shown in Figure 1. All of the five diffraction peaks could be indexed to cubic crystalline $\mathrm{Co}_{3} \mathrm{O}_{4}$, which are consistent with the values reported in the JCPDS card no. 42-1467. However, the peaks are less intense, as compared to the Au peak. In order to confirm the XRD results, surface and chemical composition analyses were investigated by XPS. A wide and short XPS scans are shown in Figure 2 (a-c). Co $2 p$ XPS spectrum of the product is represented by Figure 2 (b) where the spin-orbital splitting peaks at $\sim 780$ and $\sim 795 \mathrm{eV}$, are assigned to the Co $2 \mathrm{p}_{2 / 3}$ and $\mathrm{Co}$ $2 \mathrm{p}_{1 / 2}$ which is in agreements with the data reported for pure $\mathrm{Co}_{3} \mathrm{O}_{4}$ crystals with a spinel structure $[17,25]$. The peak at $\sim 770 \mathrm{eV}$ is corresponded to the Auger peak of cobalt [25]. The peaks at $\sim 789 \mathrm{eV}$, and $\sim 803 \mathrm{eV}$ are attributed to $2 \mathrm{p}_{2 / 3}$ and $2 \mathrm{p}_{1 / 2}$ shake-up satellite of $\mathrm{Co}^{3+}$, respectively [26]. The decomposition of the $\mathrm{Co} 2 \mathrm{p}$ spectrum of $\mathrm{Co}_{3} \mathrm{O}_{4}$ contains the 
contribution of $\mathrm{Co}^{3+}$ octahedral and of $\mathrm{Co}^{2+}$ tetrahedral. The O 1s XPS peaks (Figure 2(c)) at $\sim 530 \mathrm{eV}$, which corresponds to the oxygen species in the $\mathrm{Co}_{3} \mathrm{O}_{4}$ phase and at $\sim 531 \mathrm{eV}$ might be due to the hydroxyl group and adsorbed water [26, 27]. Figure 3 (a, and b). shows SEM images at low and high magnification for $\mathrm{Co}_{3} \mathrm{O}_{4}$ nanowires grown at relatively high concentration $2.8 \mathrm{mM}$ of the SDBS and in Figure 3 (c and d) $\mathrm{Co}_{3} \mathrm{O}_{4}$ nanowires achieved with $1.4 \mathrm{mM}$ of SDBS are shown. All the nanowires were having a diameter of around $50 \mathrm{~nm}$. These results are also in agreement with other reports [22, and 28], where they investigated the effect of the surfactant on the growth of $\mathrm{ZnO}$ nanostructures. Although many researchers studied the effect of organic additives on the growth of metal oxide nanostructures, the full explanation has not been yet realized. We believe that the SDBS in the growth solution would initiate the growth by the formation of an electrical double layer [29] at the interface. Since the whole system have been subjected to $\sim 90{ }^{\circ} \mathrm{C}$ there would be an aggregation of the SDBS molecules on the substrate [31-32]. This aggregates which are form of micelles have a crucial effect into the thermodynamics of the system and hence controlling and forming template for the growth of $\mathrm{Co}_{3} \mathrm{O}_{4}$ nanostructures.

In general point defects include Frenkel type, Schottky type, and the impurity type [33] and the doping of metal oxide semiconductors may lead to all or one of them. Consequently, defects change the optical and electronic properties of the material and this may result in electronic energy states within the band gap of the metal oxide semiconductor [34]. In order to obtain information about the electronic structure and the transition from point defects UVVis. spectroscopy was used, as shown in Figure 4(a) absorption spectrum for three $\mathrm{Co}_{3} \mathrm{O}_{4}$ nanostructures grown with $0,1.4,2.8 \mathrm{mM}$ of the SDBS on glass substrate. Two absorption peaks were observed at $\sim 2.35$, and $1.57 \mathrm{eV}$. To determine the photon energy "optical bandgap", we plot $(\alpha \mathrm{E})^{2}$ versus $\mathrm{E}$ in Figure 4(b) for all three $\mathrm{Co}_{3} \mathrm{O}_{4}$ nanostructures, where $\alpha$, and $\mathrm{E}$ are the absorption coefficient and photon energy, respectively [35]. The linear extrapolation of $(\alpha \mathrm{E})^{2}$ give two band gap values of each $\mathrm{Co}_{3} \mathrm{O}_{4}$ nanostructure $\sim 3.65-2.05$ $\mathrm{eV}$ for the structure grown without SDBS, $3.95-2.09 \mathrm{eV}$ for $\mathrm{Co}_{3} \mathrm{O}_{4}$ grown using $1.4 \mathrm{mM}$ SDBS, and finally $\sim 4-2.29 \mathrm{eV}$ for $\mathrm{Co}_{3} \mathrm{O}_{4}$ grown with a $2.8 \mathrm{mM}$ SDBS. The first band gap can be attributed to charge transfer from $\mathrm{O}^{-2} \rightarrow \mathrm{Co}^{+2}$, and the second band gap from $\mathrm{O}^{-2} \rightarrow$ $\mathrm{Co}^{+3}[36,37]$. At this point it's convenient to recall that, the band gap of bulk materials can be largely increased when compared with counterparts of the nanomaterial [38]. Furthermore, impurities as a direct influence of the SDBS may be dominant, and result in electronic energy states within the band gap of the $\mathrm{Co}_{3} \mathrm{O}_{4}$ nanostructure [34, 39]. 


\subsection{Electrochemical measurements}

Different properties of the present chemical sensors (slope, linear response range, response time, selectivity, and reproducibility) were studied by a potentiometric method where the system has employed the $\mathrm{Co}_{3} \mathrm{O}_{4} \mathrm{CMEs}$ as the indicator electrodes (Figure 5 (a-d)) versus $\mathrm{Ag} / \mathrm{AgCl}$ as a reference electrode. While changing the dopamine molecule concentration from $1 \mathrm{nM}$ to $10 \mathrm{mM}$ in the buffer solution, the electromotive force is changed; this is shown in Figure 6. Usually, the concentration of DA in biological systems is in the range of $10^{-8}$ to $10^{-6} \mathrm{M}$ [40]. As a lower level $10^{-8}$ has not been achieved by using $\mathrm{ZnO}$ based sensor that was reported previously [21], it was appealing to seek a more sensitive sensor. The obtained results revealed that the proposed sensor possesses a lower LOD compared to previously reported sensor [21]. The lower LOD was found to be $0.06 \times 10^{-9} \mathrm{M}$ and below that concentration, there was deviation from linearity. Moreover, as it can be seen from Figure 6 the slope that addressed the sensitivity of the CME was found to be $52 \mathrm{mV} / \mathrm{decade}$. The lower LOD, wide range of detection and a good sensitivity of the presented CMEs are attributed to the high surface-to-volume ratio of the $\mathrm{Co}_{3} \mathrm{O}_{4}$ nanowires and their better electro-catalytic properties [41]. On the other hand, these results might be connected to the presence of the surfactant as have been suggested in [24]. Where they described that, the addition of surfactant has a duel effect; one in modifying the morphology and the other is by enhancing the sensitivity. Moreover, as pointed out above after an aggregation, this adsorbed layer might give rise to the creation of the point defects upon dehydration of the cobalt hydroxide phase. Since it is known that defects have a significant impact on surfaces of metal oxides and would enhance the catalytic activity of the $\mathrm{Co}_{3} \mathrm{O}_{4}[34,42]$. The response time is plotted in Figure 7 where it shows that, a value less than $10 \mathrm{~s}$ is the time needed for the CME to reach the saturation mode which was measured in $0.1 \mathrm{mM}$ of DA. Moreover, the selectivity has been examined (Figure 8). Upon the addition of $100 \mu \mathrm{l}$ of $100 \mathrm{mM}$ uric acid, urea, and ascorbic acid respectively to $0.1 \mathrm{mM} \mathrm{DA}$ solution. The results indicate that, such interference is not significantly affecting the DA signal intensity which is attributed to the pores size of ionophore $\beta-\mathrm{CD}$ that has a cage-like supramolecular structure, and hydrophobic cavity which could permit certain molecules to pass and prevents the others [43]. It is worth mentioning that, the pore diameter of the $\beta-\mathrm{CD}$ is $\sim 0.7 \mathrm{~nm}$ and for the DA is around $0.5 \mathrm{~nm}$ i.e., benzene ring size and possibly all the interfering compounds examined in this work were less than the $\beta-\mathrm{CD}$ diameter. However, a hydrophobic cavity of the $\beta-\mathrm{CD}$ can be affected to some extent. Finally, we measured reproducibility in $0.01 \mathrm{mM}$ concentration of DA as is shown in Figure 
9. Responses of five prepared CMEs (two $2.8 \mathrm{mM}$ of SDBD, three with $1.4 \mathrm{mM}$ ) were examined. No observable deviations were recorded. Mostly the robustness may be attributed to the existence of PVC. We can infer that, the proposed CMEs works well under the normal conditions of blood serum.

\section{Conclusion}

We have developed a chemically modified electrode by synthesizing $\mathrm{Co}_{3} \mathrm{O}_{4}$ nanostructures with ultra-thin morphology. The morphologies of the $\mathrm{Co}_{3} \mathrm{O}_{4}$ nanostructures were readily tunable by changing the concentration of SDBS as an additive in the growth solution. The $\mathrm{Co}_{3} \mathrm{O}_{4}$ nanostructures were showed nanowires shape with a different density depending on the concentration of the SDBS. The ultra-thin morphology is due to the “directing agent" features of the SDBS. The selectivity for DA was achieved by combing a plasticizer PVC polymer and $\beta$-CD ionophore. A wide range of detection ranging from $10^{-9} \mathrm{M}$ and up to $10^{-2} \mathrm{M}$ was achieved. This range of detections is suitable for DA concentration in human body $\left(10^{-8} \mathrm{M}-10^{-6} \mathrm{M}\right)$. Moreover, the sensor selectivity was as high as $52 \mathrm{mV} / \mathrm{decade}$ and a response time of about $10 \mathrm{~s}$. These sensing properties are attributed to the defects and high surface-to-volume ratio along with their electro-catalytic properties. The findings in this paper indicate the importance of the use of controlled nanostructures morphology for developing efficient functional materials. 


\section{References}

[1] J. W. Lee, and R. S. Foote, Micro and nano technologies in bioanalysis methods and protocols, Humana press , New York, 2009. 544. Ch.12., page 163.

[2] A. Manz, N. Graber, and H.M. Widmer, Miniaturized total chemical analysis systems: a novel concept for chemical sensing. Sens. Actu. B 1 (1990) 244-248.

[3] T. Sokalski, A. Ceresa, T. Zwickl, and E. Pretsch, Large Improvement of the lower detection limit of ion-selective polymer membrane electrodes, J. Am. Chem. Soc., 119 (1997) 11347-11348.

[4] K. E. Petersen, W. A. McMillan, G. T. A. Kovacs, M. A. Northrup, L. A. Christel, and F. Pourahmadi, Toward next generation clinical diagnostic instruments: scaling and new processing paradigms, Biomedical Microdevices, 1 (1998) 71-79.

[5] M. J. Madou, and R. Cubicciotti, Scaling issues in chemical and biological sensors Proc. IEEE (2003) 91.

[6] J. Janata, Principles of chemical sensors. $2^{\text {nd }}$ Ed. New York : Springer, 2009.

[7] A. Hulanicki, S. Glab and F. Ingman., Chemical sensors deffinitions and classification. Pure \& Appl. Cherm., 63 (1991) 1247-1250.

[8] R.W. Cattrall, H. Freiser, Coated wire ion-selective electrodes. Anal. Chem., 43 (1971) $1905-1906$.

[9] W. Kutner, J. Wang, M. Lher, and R. P. Buck, Analytical aspects of chemically modified electrodes classification, critical evaluation. Pure \& Appl. Chem., 70 (1998) 1301 - 1318.

[10] M. Fibbioli, W. E. Morf, M. Badertscher, N. F. de Rooij, and E. Pretsch, Potential drifts of solid-contacted ion-selective electrodes due to zero-current ion fluxes through the sensor membrane, Electroanalysis, , 12 (2000) 1286 - 1292.

[11] A. Liu, Towards development of chemosensors and biosensors with metal-oxide-based nanowires or nanotubes, Biosensors and Bioelectronics 24 (2008)167-177. 
[12] Richard C. Alkire, Dieter M. Kolb, Jacek Lipkowski and Philip N. Ross, Advances in electrochemical science and engineering: Vol. 11 Chemically modified electrodes. Ch.1. 2009 WILEY-VCH Verlag GmbH \& Co. KGaA, Weinheim.

[13] Pratima R. Solanki, Ajeet Kaushik, Ved V. Agrawal and Bansi D. Malhotra, Nanostructured metal oxide-based biosensors, NPG Asia Mater. 3(1) (2011)17-24.

[14] P. Patnaik, handbook of inorganic chemicals. The McGraw-Hill Companies, 2003, page 247, ISBN 0-07-049439-8.

[15] K. Koumoto, H. Yanagida, Electrical conduction in pure and Li-substituted $\mathrm{Co}_{3} \mathrm{O}_{4}$, Communications of the American Ceramic Society 64 (1981) C-156-C-157.

[16] J. Jansson, A. E. C. Palmqvist, E. Fridell, M. Skoglundh, L. Österlund, P. Thormählen, and V. Langer, On the catalytic activity of $\mathrm{Co}_{3} \mathrm{O}_{4}$ in low-temperature $\mathrm{CO}$ oxidation, J. Catalysis. 211(2002) 387-397.

[17] A. M. Cao, J. S. Hu, H. P. Liang, W. G. Song, L. J. Wan, X. L. He, X. G. Gao, and S. H. Xia, Hierarchically structured cobalt oxide (Co3O4): The morphology control and its potential in sensors J. Phys. Chem. B, 110 (2006) 15858-15863.

[18] P. M. S. Monk, R. J. Mortimer and D. R. Rosseinsky, Electrochromism and electrochromic devices, Cambridge University press, 2007 ISBN-13 978-0-511-50806-6.

[19] K. Koumoto, H. Yanagida, Electrical conduction in pure and Li-substituted $\mathrm{Co}_{3} \mathrm{O}_{4}$, Communications of the American Ceramic Society 64 (1981) C-156-C-157.

[20] J. Chen, X. Wu, and A. Selloni, Electronic structure and bonding properties of cobalt oxide in the spinel structure, Phy. Rev. B 83 (2011) 245204.

[21] S. Elhag, Z.H. Ibupoto, O. Nur, and M. Willander, Incorporating $\beta$-Cyclodextrin with $\mathrm{ZnO}$ Nanorods: A potentiometric strategy for selectivity and detection of dopamine. Sensors 14 (2014) 1654-1664.

[22] A. I. Inamdar, S. H. Mujawar, V. Ganesan, and P. S. Patil, Surfactant-mediated growth of nanostructured zinc oxide thin films via electrodeposition and their photoelectrochemical performance, Nanotechnology 19 (2008) 325706 (7pp). 
[23] D. P. Dubal, G. S. Gund, R. Holze, H. S. Jadhav, C. D. Lokhande, and C.-J. Park, Surfactant-assisted morphological tuning of hierarchical $\mathrm{CuO}$ thin films for electrochemical supercapacitors, Dalton Trans., 42 (2013) 6459.

[24] X.-G. Wang, Q.-S. Wu, W.-Z. Liu, Y.-P. Ding, Simultaneous determination of dinitrophenol isomers with electrochemical method enhanced by surfactant and their mechanisms research, Electrochimica Acta 52 (2006) 589-594.

[25] L. Fu, Z. Liu, Y. Liu, B. Han, P. Hu, L. Cao, and D. Zhu, Beaded cobalt oxide nanoparticles along carbon nanotubes towards more highly integrated electronic devices, Adv. Mater. 17 (2005) 217-221.

[26] H. Xia, D. Zhu, Z. Luo, Y. Yu, X. Shi, G. Yuan, and J. Xie, Hierarchically structured Co3O4 Pt MnO2 nanowire arrays for high-performance supercapacitors, Sci. Rep. 3 (2013) 2978.

[27] M. C. Biesingera, B. P. Paynec, A. P. Grosvenord, L. W.M. Laua, A. R. Gerson, R. St. C. Smart, Resolving surface chemical states in XPS analysis of first row transition metals, oxides and hydroxides: Cr, Mn, Fe, Co and Ni, Appl. Sur. Sci. 257 (2011) 2717-2730.

[28] A. Dev, S. K. Panda, S. Kar, S. Chakrabarti, and S. Chaudhuri, Surfactant-assisted route to synthesize well-aligned $\mathrm{ZnO}$ nanorod arrays on sol-gel-derived $\mathrm{ZnO}$ thin films, J. Phys. Chem. B 110 (2006) 14266-14272.

[29] K.S. Birdi, Handbook of surface and colloid chemistry, $3^{\text {rd }}$ Ed. 2009 by Taylor \& Francis Group, LLC Ch. 7 page 206.

[30] P. J. Missel, N. A. Mazer, G. B. Benedek, C. Y. Young, and Marlin C. Carey Thermodynamic analysis of the growth of sodium dodecyl sulfate micelles, J. Phys. Chem. 84 (1980) 1044-1057.

[31] A. V. Delgado, Interfacial electrokinetics and electrophoresos, surfactant science series volume, 1062002 Marcel Dekker, Inc. page. 8.

[32] S. Manne, J. P. Cleveland, H. E. Gaub, G. D. Stucky, and P. K. Hansma, Direct visualization of surfactant hemimicelles by force microscopy of the electrical double layer, Langmuir 10 (1994) 4409-4413. 
[33] "crystal defect." Encyclopaedia Britannica. Encyclopaedia Britannica Online Academic Edition. Encyclopædia Britannica Inc., 2014. Web. 25 Mar. 2014.

<http://www.britannica.com/EBchecked/topic/145211/crystal-defect $>$.

[34] V. E. Henrich, Metal-oxide surfaces, Prog. Sur. Sci. 50 (1995) 77-90.

[35] D. Barreca, C. Massignan, S. Daolio, M. Fabrizio, C. Piccirillo, L. Armelao, and E. Tondello, Composition and microstructure of cobalt oxide thin films obtained from a novel cobalt (II) precursor by chemical vapor deposition, Chem. Mater., 13 (2001) 588-593.

[36] F. Gu, C. Li, Y. Hu, L. Zhang, Synthesis and optical characterization of Co3O4 nanocrystals, Journal of Crystal Growth 304 (2007) 369-373.

[37] K. M. E. Miezinska, B. R. Hollebone, An Assignment of the optical absorption spectrum of mixed valence Co3O4 spinel films, J. Phys. Chem. Solids, 48 (1987) 649-656.

[38] Y. Wang and N. Herron, Nanometer-sized semiconductor clusters materials synthesis, quantum size effects, and photophysical properties, J. Phys. Chem., 95 (1991) 525-532.

[39] P. Kharel, C. Sudakar, G. Lawes, R. Suryanarayanan, R. Naik and V. M. Naik. Concentration and defect dependent ferromagnetism above room temperature in Co doped ZnO films prepared by metalorganic decomposition. MRS Proceedings, 891, 0891-EE10-14 doi:10.1557/PROC-0891-EE10-14.

[40] K. Jackowska, P. Krysinski, New trends in the electrochemical sensing of dopamine. Anal. Bioanal. Chem., 405 (2013) 3753-3771.

[41] L. Xue, C. Zhang, H. He, Y. Teraoka, Catalytic decomposition of N2O over CeO2 promoted Co3O4 spinel, Applied Catalysis B: Environmental 75 (2007) 167-174.

[42] G. Olguin, C. Yacou, S. Smart, and J. C. D. da Costa, Tailoring the oxidation state of cobalt through halide functionality in sol-gel silica, Scientific Reports 3 (2013) 2449.

[43] J. Zhang , P. X. Ma, Cyclodextrin-based supramolecular systems for drug delivery: Recent progress and future perspective, Adv. drug delivery Rev. 65 (2013) 1215-1233. 


\section{Figure captions}

Figure 1: XRD pattern of the product, which is addressed $\mathrm{Co}_{3} \mathrm{O}_{4}$ nanostructures and $\mathrm{Au}$.

Figure 2: XPS study of the as grown $\mathrm{Co}_{3} \mathrm{O}_{4}$ nanostructures on $\mathrm{Au}$. (a) The wide scan, (b) $\mathrm{Co}$ 2p, and (c) O1s spectra.

Figure 3: Shows the morphology of the of $\mathrm{Co}_{3} \mathrm{O}_{4}$ nanostructures as grown with a different amounts of SDBS (a) 0.1 , and (b) $0.05 \mathrm{~g}$ with high and low magnifications and both of them are dense with a high aspect ratio.

Figure 4: (a) UV. Vis. absorption spectra, the inset shows the adsorption peaks, and (b) plot of $(\alpha \mathrm{E})^{2}$ versus photon energy for the $\mathrm{Co}_{3} \mathrm{O}_{4}$ nanostructures.

Figure 5: Illustrate the fabrication of electrode modifications (a) spin coating of cobalt acetate on $\mathrm{Au}$ coated glass, (b) growth of $\mathrm{Co}_{3} \mathrm{O}_{4}$ nanostructures, (c) immobilization of polymeric membrane by deep coating, and (d) proposed mechanism of CME where a DA accumulated and $\beta-C D$ controlled that selections.

Figure 6: Calibration curve is showing the sensitivity and the linear response range of our constructed CMEs.

Figure 7: Response time less than $10 \mathrm{~s}$ measured in $0.1 \mathrm{mM}$ concentration of DA.

Figure 8: Shows that, a selectivity of constructed CMEs upon the addition of $100 \mu 1$ of 100 $\mathrm{mM}$ uric acid, urea, and ascorbic acid respectively to $0.1 \mathrm{mM}$ DA solution.

Figure 9: Reproducibility of five prepared CMEs (two with $2.8 \mathrm{mM}$ of SDBD, and three with $1.4 \mathrm{mM})$. 
Fig. 1:

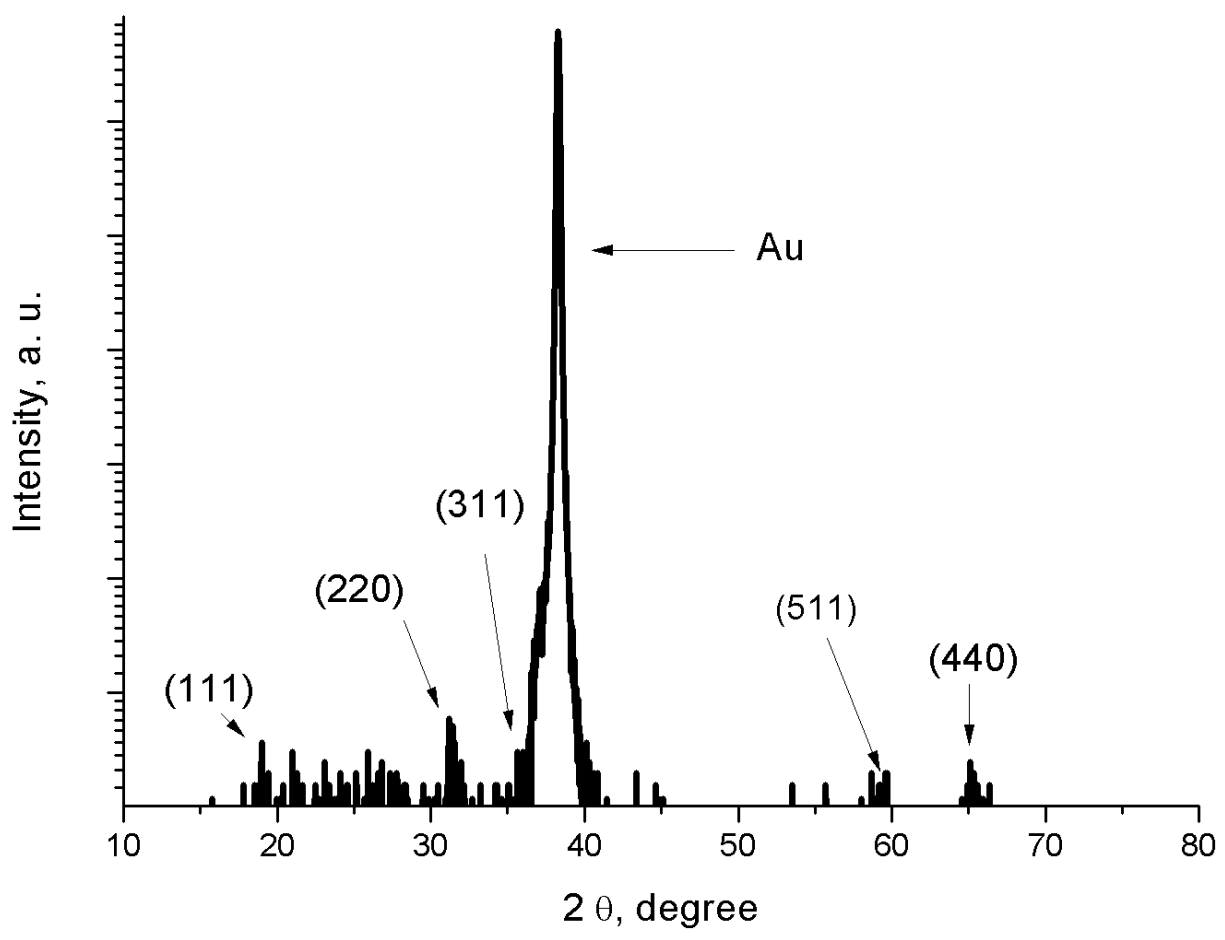


Fig. 2 (a):

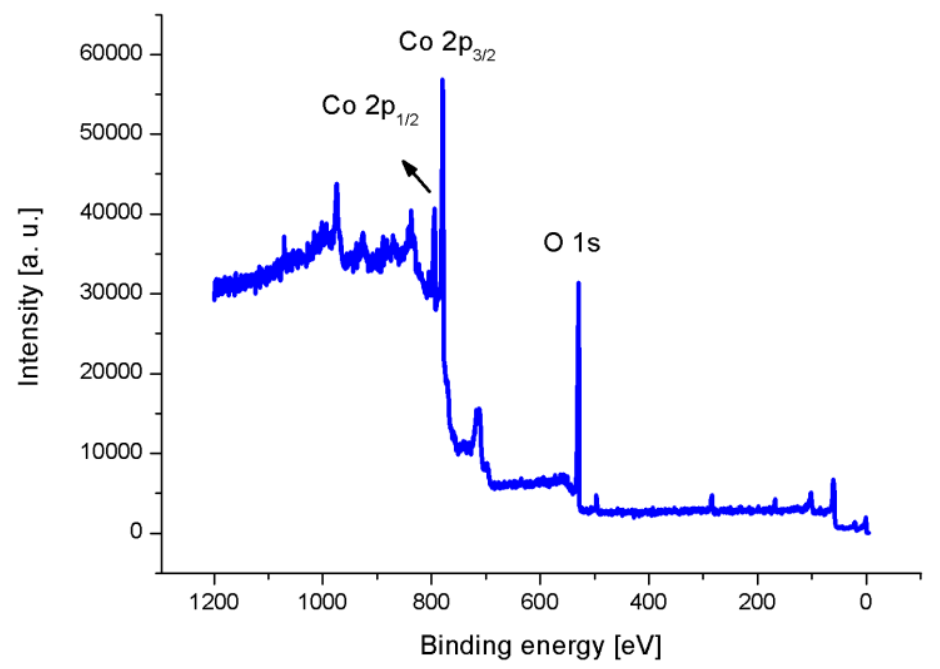

Fig. 2(b):

Fig. 2(c):
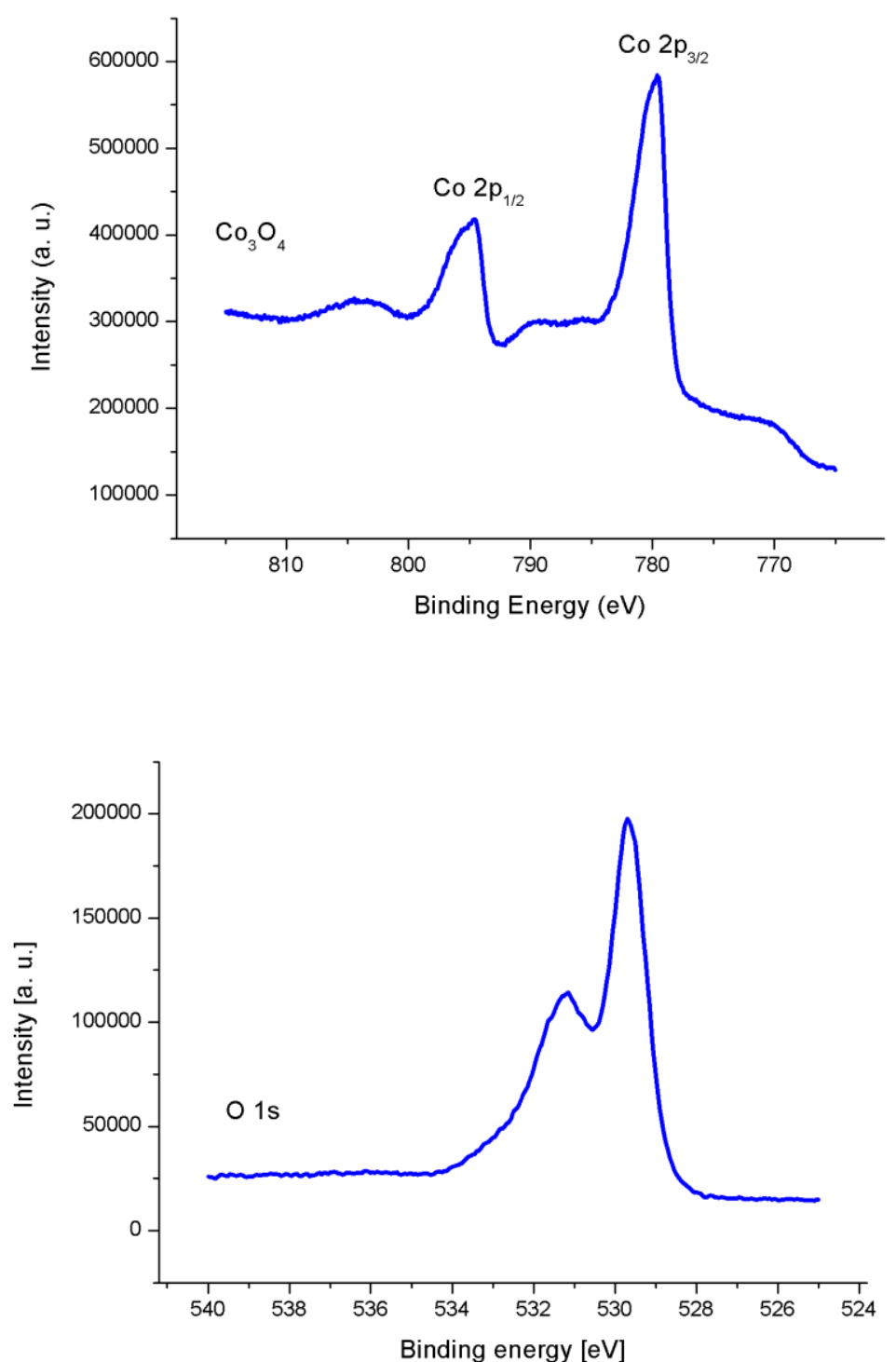
Fig. 3(a):
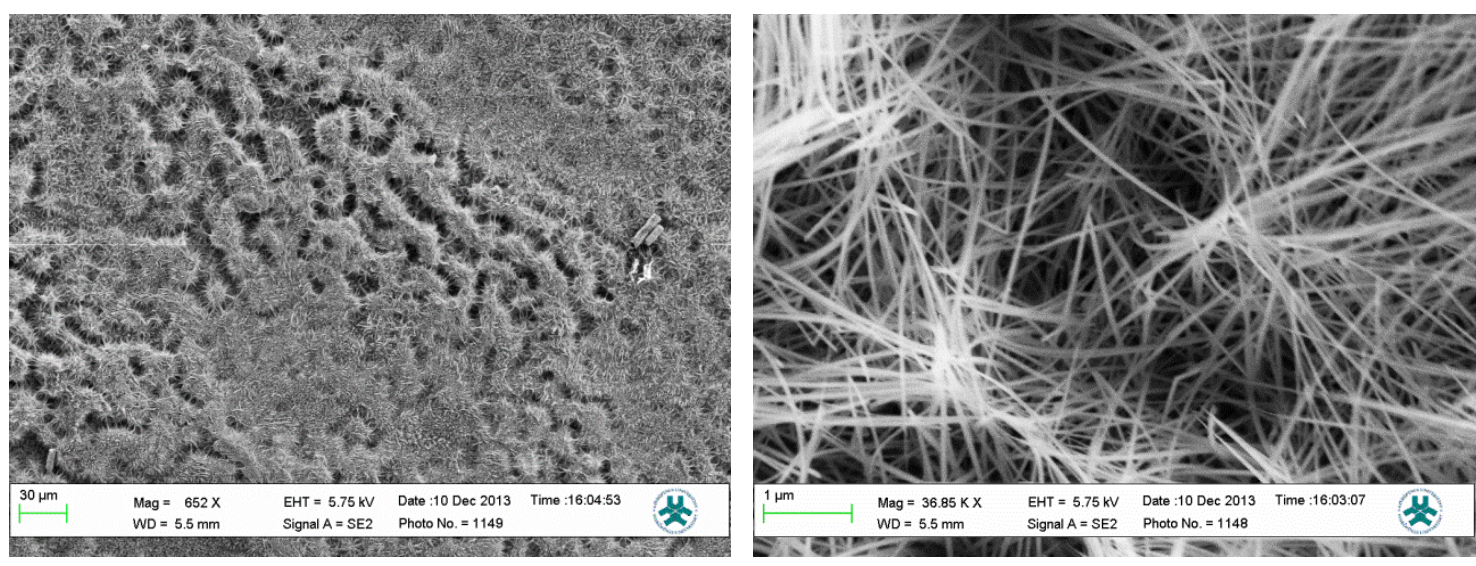

Fig. 3(b):
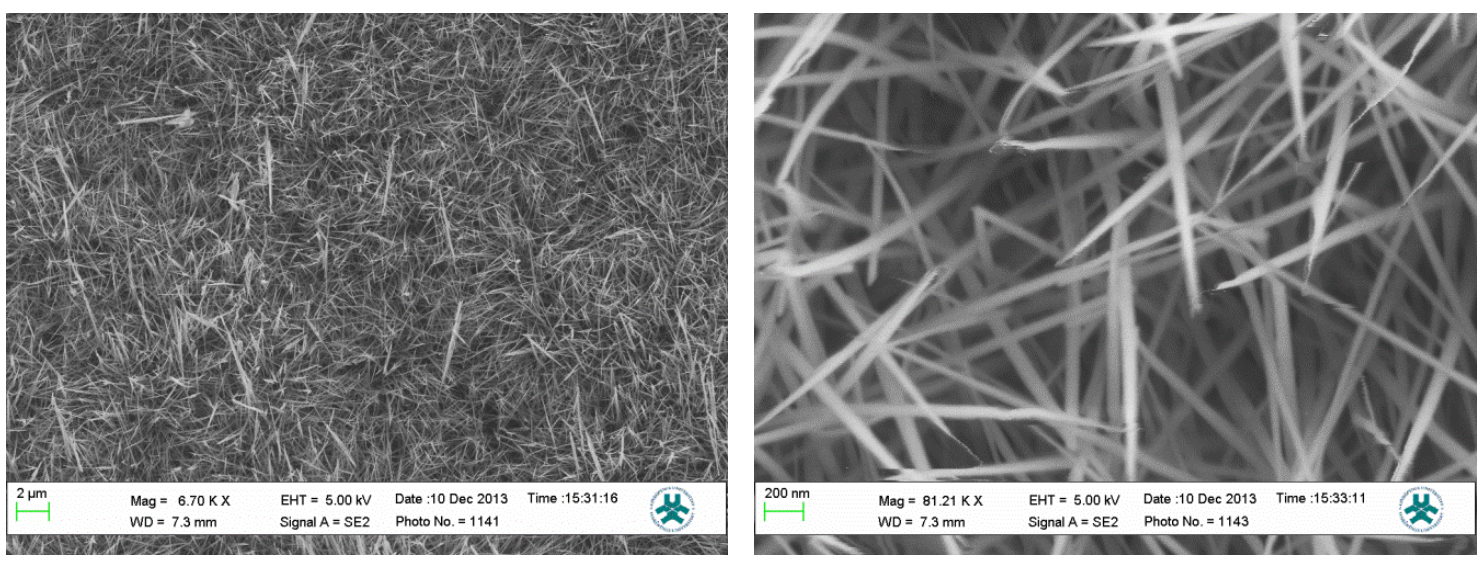
Fig 4 (a):

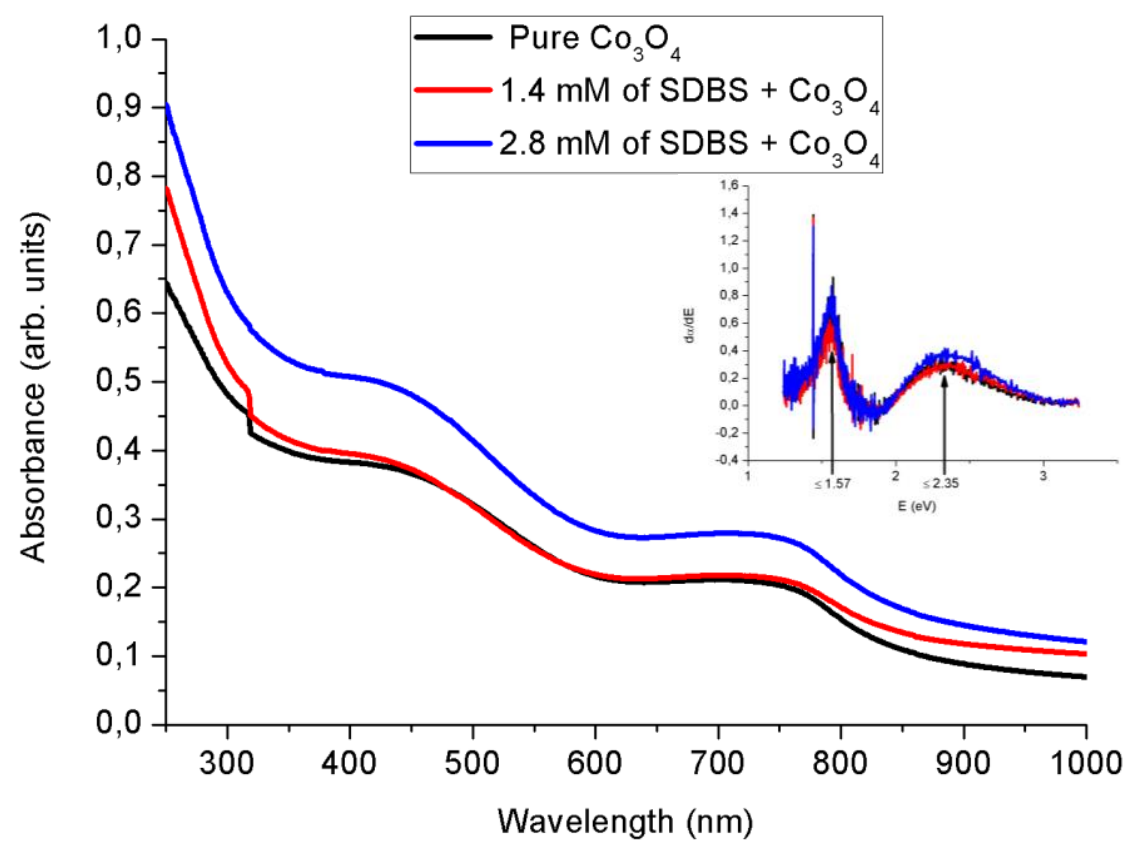

Fig 4 (b):

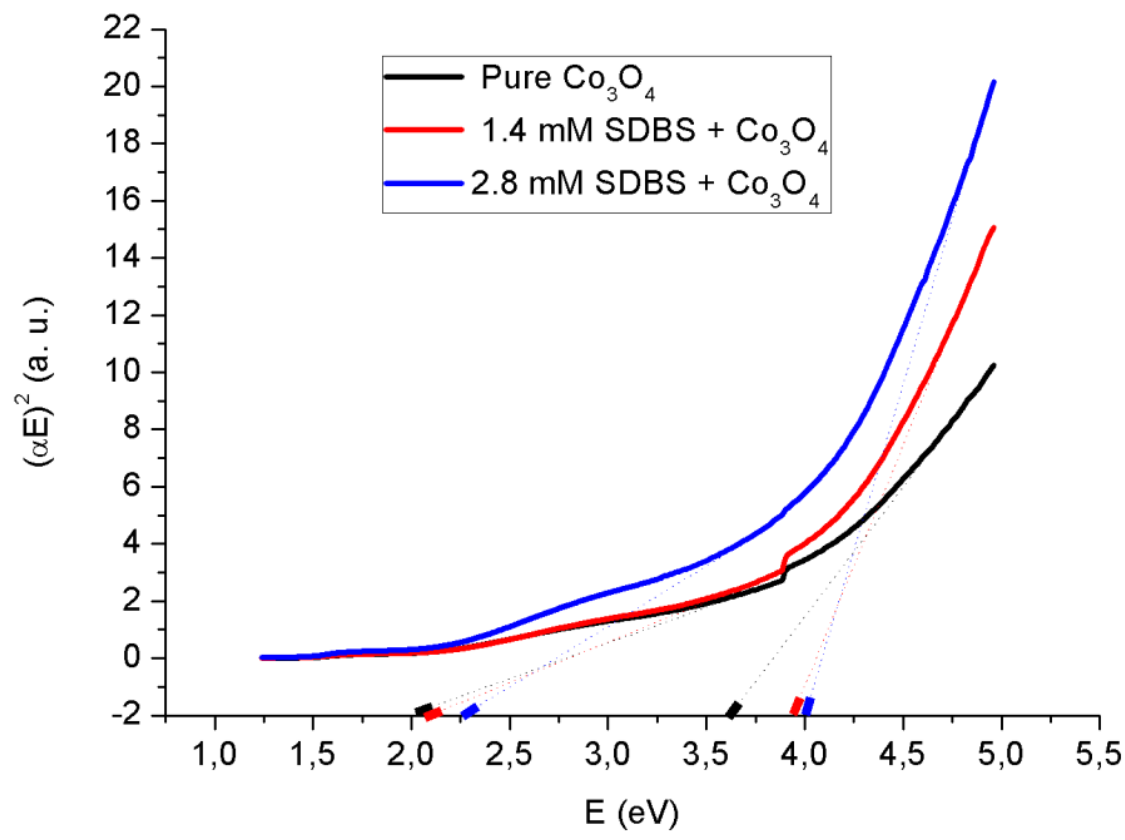


Fig. 5:

(a)

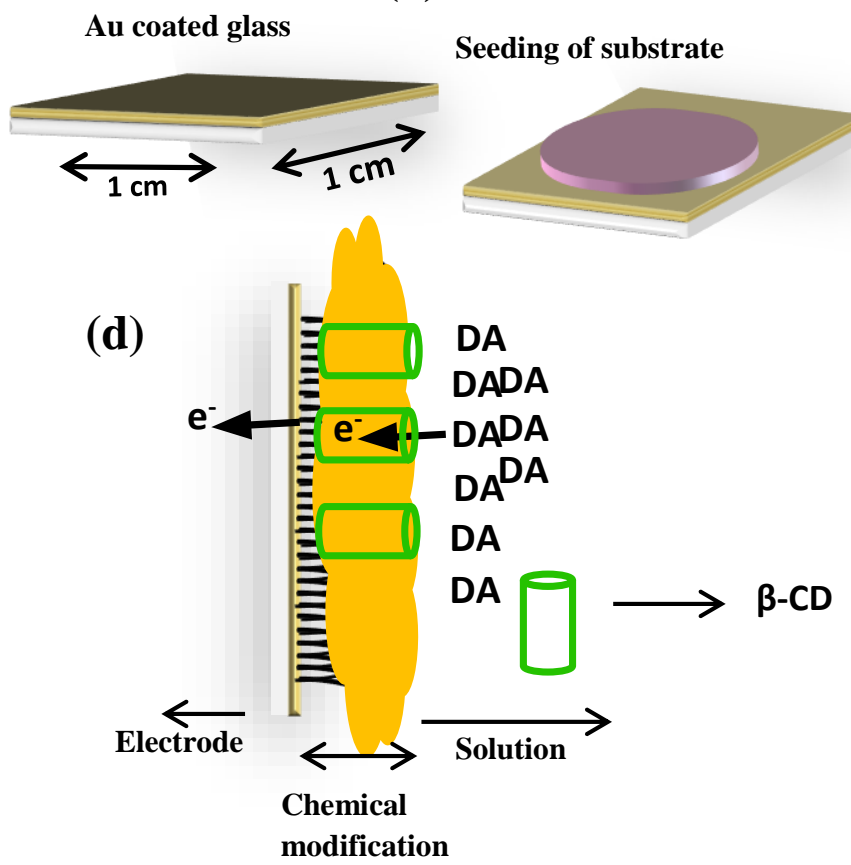

(b) $\mathrm{C}_{3} \mathrm{O}_{4}$ nanostructures

Hydrothermally treated of growth solution

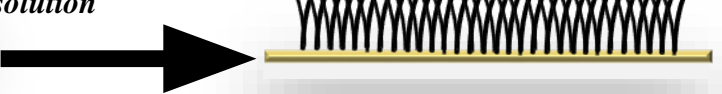

(c) 
Fig. 6:

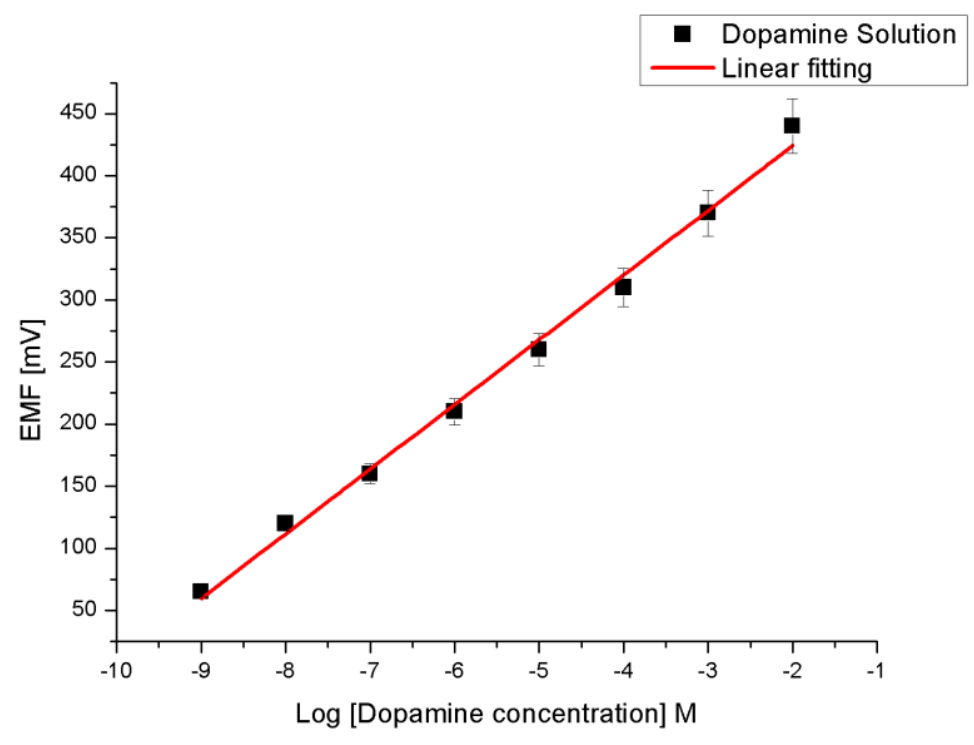


Fig. 7:

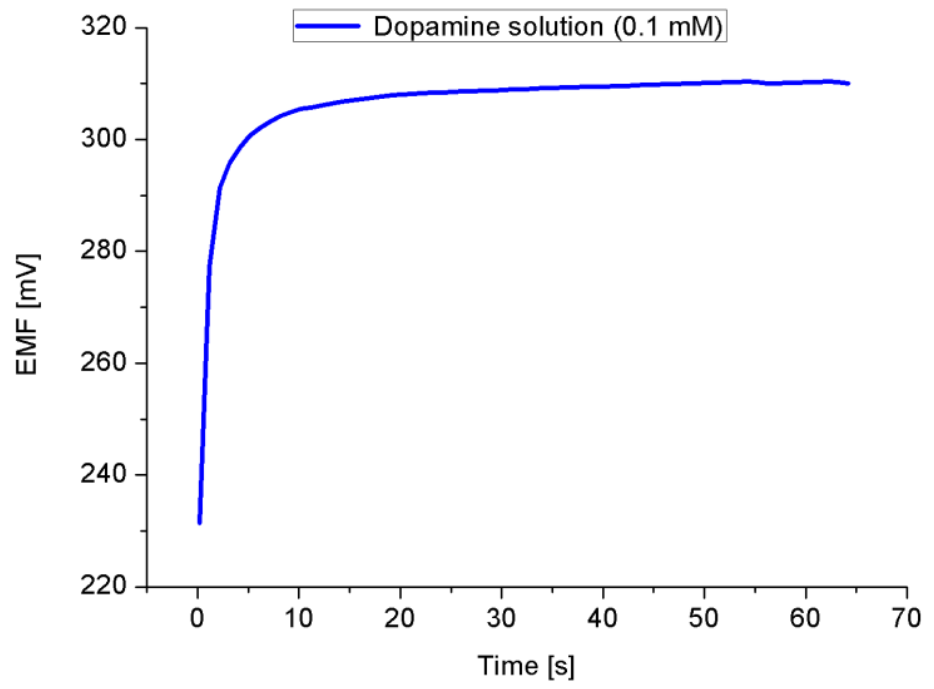


Fig. 8:

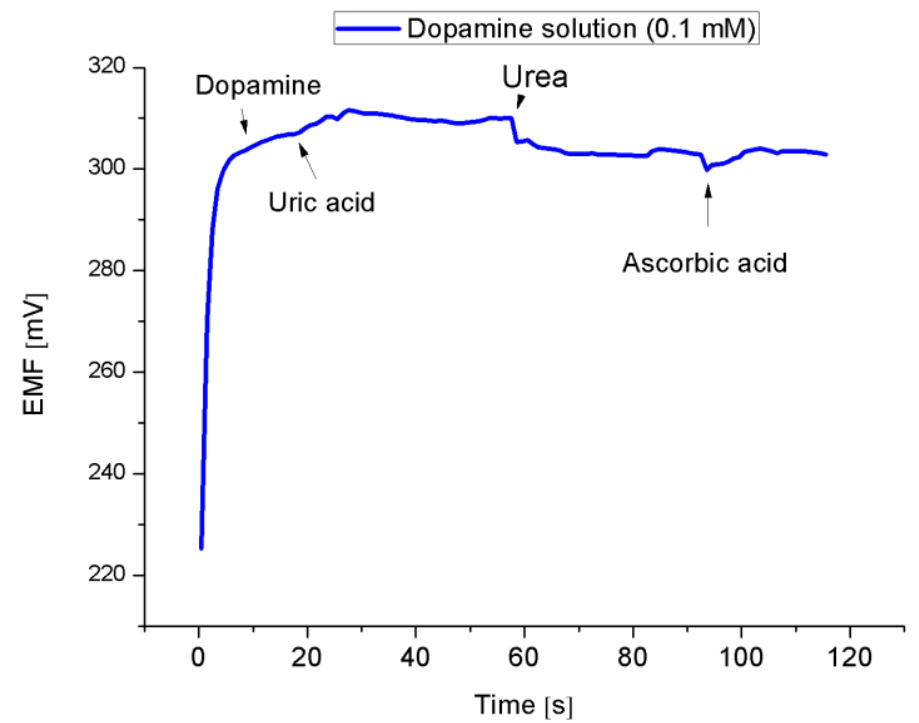


Fig. 9:

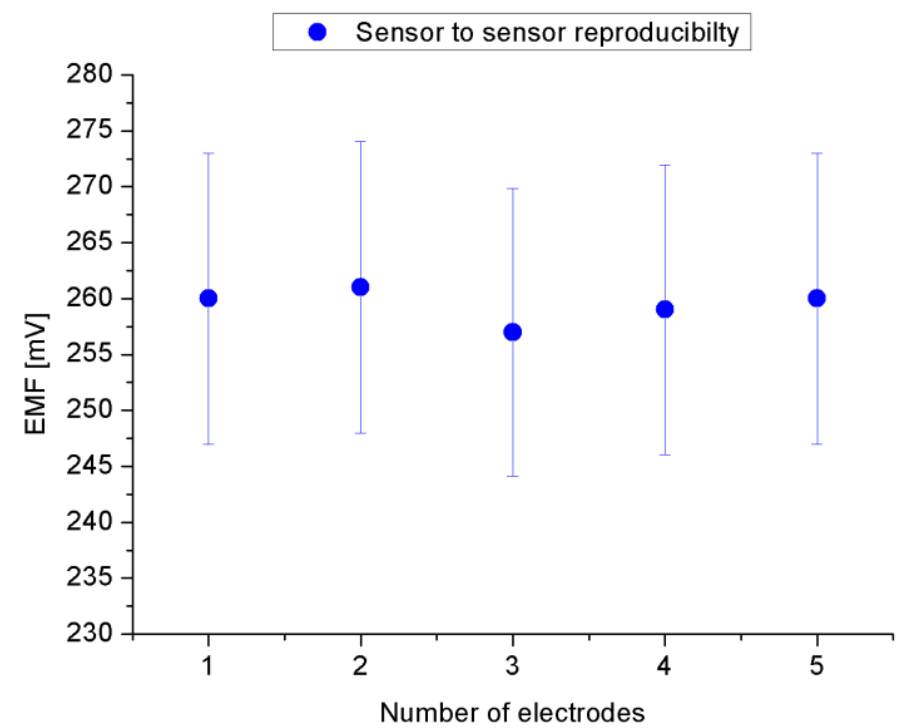

